\title{
LA GESTACIÓN SUBROGADA BAJO PRISMAS DIFERENTES. Cuatro corrientes de análisis para un mismo tema
}

\author{
Sandra FERNÁNDEZ GARCÍA; Elena HERNÁNDEZ CORROCHANO; \\ Nancy Anne KONVALINKA; Raúl SÁNCHEZ MOLINA \\ UNED (España) \\ sandrafg@madrid.uned.es, ecorrochano@fsof.uned.es, nkonvalinka@fsof.uned.es, ersanchez@fsof.uned.es
}

\author{
GESTATIONAL SURROGACY UNDER DIFFERENT PRISMS. Four Analytic \\ Perspectivess for a Single Subject
}

Resumen: Este artículo propone diferentes perspectivas de análisis sobre la gestación subrogada o gestación por sustitución, como se denomina en la legislación actual española. Partiendo de un trabajo previo de exploración del campo, los autores se alejan del discurso dicotómico impuesto por diferentes agentes sociales sobre su regulación, para adentrarse en la complejidad epistemológica que este tema presenta en diferentes ámbitos disciplinarios. Dos de las perspectivas aportadas utilizan la gestación subrogación como una ventana a las cuestiones más amplias de los movimientos transnacionales de personas y los significados de los parentescos genéticos, biológicos y sociales; mientras que las otras dos tratan cuestiones más específicas relacionadas con la maternidad y la procreación.

Abstract: This article sets forth different analytic perspectives with respect to gestational surrogacy or gestación por sustitución, using the term employed in present-day Spanish legislation. Based on ethographic fieldwork, the authors move away from the dichotomous discourse imposed by different social agents regarding its regulation in order to fully enter into the epistemological complexity that this issue presents in different disciplines. Two of the perspectives presented use gestational surrogacy as a window onto broader issues of transnational movement of people and of the meanings of genetic, biological, and social kinships, while the other two perspectives deal with more specific issues related to motherhood and procreation.

Palabras clave: Subrogación Gestacional. Parentesco. Transnacionalismo. Maternidad. Procreación/ Reproducción Gestational Surrogacy. Kinship. Transnationalism. Motherhood. Procreation/Reproduction 


\section{Introducción ${ }^{1}$}

Este artículo, realizado conjuntamente por los miembros del Grupo de Investigación UNED "Familia y parentesco en el siglo XXI", propone diferentes perspectivas de análisis sobre la gestación subrogada o gestación por sustitución, como se denomina en la legislación actual española ${ }^{2}$. Partiendo de un trabajo previo de exploración del campo, los autores se alejan del discurso dicotómico impuesto por diferentes agentes sociales sobre su regulación, para adentrarse en la complejidad epistemológica que este tema presenta en diferentes ámbitos disciplinarios. Dos de las perspectivas aportadas utilizan la gestación subrogación como una ventana a las cuestiones más amplias de los movimientos transnacionales de personas y los significados de los parentescos genéticos, biológicos y sociales; mientras que las otras dos tratan cuestiones más específicas relacionadas con la maternidad y la procreación.

En primer lugar, Nancy Konvalinka nos introduce en el análisis de la gestación subrogada desde la antropología del parentesco, partiendo de los distintos elementos y procesos involucrados en esta práctica. La autora nos conduce, a través de diferentes apartados hacia la importancia que, en un contexto donde las nuevas tecnologías de reproducción asistida (NTRAs) y la gestación subrogada son parte de la realidad social, tiene el estudio de las etnoteorías del parentesco y la reproducción humana, así como su reconsideración.

Raúl Sánchez Molina, por su parte, aborda el tema desde la perspectiva transnacional, centrando su interés en la economía política y la economía moral, incluyendo en el análisis tanto los países que permiten esta práctica, como los países origen de los progenitores intencionales. Este planteamiento teórico pretende superar epistemologías de carácter nacionalistas, analizando todas las intersecciones globales/locales, en tanto que proceso internacional que deja al descubierto aspectos éticos, políticos, económicos y culturales. Sandra Fernández García propone un enfoque que aúna ontogenia y ontología, centrado en el análisis de las vivencias de la maternidad a través de la gestación subrogada y la diversidad de "papeles de madre" que presenta esta práctica frente a los modelos tradicionales. Un análisis del ethos de la maternidad en el que hay que tener en cuenta la confluencia de dos factores: los cambios que han supuesto las NTRAs para las configuraciones sociales del parentesco occidental y las respuestas que se inician con el feminismo y que cuestionan las epistemologías biologicistas sobre las mujeres. Finalmente, el enfoque teórico de Elena Hernández Corrochano, parte de entender la reproducción biológica como un proceso que se debe analizar aisladamente, sin por ello obviar las implicaciones que en dicho proceso tienen otro tipo de reproducción, como la reproducción social. Siguiendo el texto de Susana Narotzky, compagina las tesis expuestas por varias antropólogas feministas sobre procreación, con el fin práctico de valorar la gestación subrogada como una de las muchas fases del proceso procreativo que se han "mercantilizado", aunque siga percibiéndose como una cuestión natural y privada.

1 Investigación financiada por distintos proyectos de investigación:

- Hernández Corrochano, Elena y Nancy Konvalinka, Raúl Sánchez Molina y Sandra Fernández García. 20162018. Madres, sujetos agentes o individuos con agencia. Estudio etnográfico a través de la subrogación gestante. MINECO, Proyecto I+D FEM2016-80012-R.

- Konvalinka, Nancy, Elena Hernández Corrochano, Raúl Sánchez Molina y Marta Garcia Alonsol. 20152017. Surrogate Paternities/Maternities in Spain: Agencies and Socio-political Structure through Ethnography. Proyecto Santander-UNED, I+D+i Orientada a los retos de la sociedad. 2014I/PPRO/029.

- Jociles Rubio, M.I. et al. 2013-2015. Revelación y secreto de los orígenes en las familias con descendencia por donación de gametos: variaciones según los modelos familiares. MINECO, Proyecto I+D CSO2012-36413. 2 Artículo 10, Ley 14/2006, de 26 de mayo, sobre técnicas de reproducción humana asistida. 


\section{La gestación subrogada abordada desde la antropología del parentesco}

Uno de los efectos de la crítica de Schneider (1972) a la antropología del parentesco como un campo de estudio invalidado por el sesgo occidental sobre lo que es el parentesco, ha sido que antropólogas y antropólogos tienden a explorar con mucho cuidado cómo cada grupo humano entiende el parentesco en cada contexto específico. De esta manera, en su análisis de relatedness, Carsten (1995) incluye la comensalía, es decir, el compartir casa y mesa, como elemento generador de parentesco entre los malayos en Pulau Langkawi. Asimismo, el bombardeo desde los medios de información sobre cuestiones de genética y su vertiente de identidad personal, ha influido en, y se encuentra influido por, los entendimientos locales del parentesco. Según pone de manifiesto Stone (2004ㄹ 332-334), los múltiples análisis antropológicos de las nuevas tecnologías de reproducción asistida han proporcionado ejemplos, tanto de distintas maneras de repensar el parentesco como de la influencia de entendimientos locales del parentesco en decisiones sobre el uso de estas NTRAs.

El trabajo de campo de otras antropólogas (Ragoné, 1994; Teman, 2010; Pande, 2014; Deomampo, 2016, para citar solo algunas obras) y el nuestro propio, indican que la gestación subrogada, en la que una mujer gesta un embrión que no lleva material genético suyo, para entregar el bebé que nace a una(s) persona(s) que le han encomendado esa labor con la intención de ser madre(s) y/o padre(s) de ese bebé, es un campo muy fructífero para desempaquetar los distintos hilos conceptuales sobre el parentesco que aparecen allí. Sustancia (genética y nutricia), proceso (gestación y crianza), estructura (lugar en una red de parentesco), e intención (como motor de un proceso que, mediante sustancias, produce un ser que se inserta en una estructura familiar y de parentesco), al estar en una situación de "desencuentro" cuando la necesidad o el deseo lleva a una(s) persona(s) a recurrir a la gestación subrogada, abocan a las personas a reflexionar sobre sus concepciones del parentesco y, a veces, a adaptarlas a las situaciones nuevas en las que se encuentran. En este sentido, la gestación subrogada es un lugar idóneo para captar instantáneas de las etnoteorías del parentesco (es decir, los entendimientos que cada grupo de personas maneja sobre el parentesco) y de la reproducción humana en proceso.

Es precisamente ese aspecto de "en proceso" el que quiero enfatizar. Rechazo de entrada cualquier idea de etnoteoría que implica un modelo que existe en las cabezas de las personas acerca de cualquier tema y da lugar directamente a acciones coherentes con ese modelo. Prefiero, más bien, un concepto de etnoteoría más dinámico y basado en la acción situada y situacional de las personas, como la que exponen Ramos, Shain y Johnson en su artículo sobre la percepción de riesgo sexual: "Desde una perspectiva etnoteórica, se supone que los individuos utilizan su conocimiento de sentido común para interpretar las situaciones y arreglárselas en ellas, y que existen simultáneamente múltiples definiciones de la realidad" (Ramos, Shain y Johnson, 1995: 486)³.

En su investigación, estos autores descubren que sus colaboradores en la investigación, personas actualmente o anteriormente con adicción a drogas e involucradas en redes de prostitución, mantienen una definición de la realidad en la que las relaciones sexuales con ciertas personas "cercanas" no se consideran de riesgo hasta que el diagnóstico de una enfermedad de transmisión sexual demuestra lo contrario. Como comentan Ramos, Shain y Johnson (1995: 487), "Aunque la mayoría de las personas son conscientes de realidades múltiples, se preocupan principalmente de arreglárselas en sus propias circunstancias prácticas (Wagner, 1973)" (Ramos et al., 1995,: 487). Sostienen que "no cuestionarán su definición de la realidad hasta que no les obligue a hacerlo algún evento inesperado" (Ramos et al., 1995: 487).

3 Traducción de Nancy Konvalinka.

4 Traducción de Nancy Konvalinka. 
Esto, según la información recogida en nuestro trabajo de campo y el de otros (Ragoné, 1994: 95-107; Melhuus, 2012: 23-45), es lo que ocurre con las personas quienes, en su búsqueda de la formación familiar, se ven abocadas a recurrir a las NTRAs y a la gestación subrogada. Desde sus etnoteorías del parentesco y de la reproducción humana, ampliamente compartidas en su contexto sociocultural, el evento, muchas veces inesperado, de necesitar una donación de esperma, óvulo o embrión o la prestación temporal de la capacidad gestante de una mujer, para formar sus familias, hace que algunas de estas personas -aunque no todas- redefinan la realidad de lo que significa el parentesco y la reproducción. Es este proceso de retrabajar las etnoteorías propias del parentesco y la reproducción lo que me interesa ver en el caso de la gestación subrogada.

En American Kinship, Schneider (1980 [1968]: 21-29) identificó "naturaleza" y "ley" como los dos hilos conductores del parentesco americano, de lo que se podría llamar la etnoteoría del parentesco americano. Aunque "intención" es un concepto implícito en la adopción, es Ragoné (1994), con el término "conception in the heart", quien introduce la idea de "intención" como fuerza formadora de parentesco en la gestación subrogada. De forma similar, Weston (1991) utiliza el término choice, elección, para hablar de las familias homoparentales, como alternativa a las familias biogenéticas de origen; Stone (2004b) recoge el término elección para añadir un tercer hilo conductor a los campos de naturaleza y ley propuestos por Schneider. Para el caso de la gestación subrogada, me parece conveniente combinar los términos en uno, intention-choice, ya que el proceso de la gestación subrogada en sí combina no solo la intención de tener un hijo y así formar una familia (una intencionalidad que puede rechazar o fomentar un papel activo en este parentesco para la gestante subrogada), sino también una serie de elecciones, que no son baladíes, sobre países de destino, donantes, embriones donados y gestantes posibles.

Estos tres hilos conductores, naturaleza, ley e intención-elección aparecen como fundamentales en las etnoteorías del parentesco y de la reproducción humana que se revelan en la gestación subrogada. Aunque cada contexto y grupo de personas puede combinar estos elementos en una variedad de maneras, surgen una y otra vez en las etnografías sobre la reproducción asistida y, en particular, la gestación subrogada. Lo que llamaba Schneider "naturaleza" está siendo ampliamente explorado como parentesco biogenético por muchos investigadores (entre otros, Birenbaum-Carmeli e Inhorn, 2009; Edwards y Salazar, 2009; Birenbaum-Carmeli y Carmeli, 2010; Knecht, Klotz y Beck, 2012; Schramm, Skinner y Rottenburg, 2012; Franklin, 2013) en relación con las NTRAs y la gestación subrogada. Nuestro trabajo de campo, al igual que el trabajo de campo descrito en muchas etnografías, muestra que, cuando el sujeto o los sujetos progenitores (en cualquier configuración: pareja heteroparental, pareja homoparental, madre sola o padre solo) tienen algún vínculo genético con el bebé nacido de la gestación subrogada, este vínculo es un vehículo importante de parentesco, aunque no necesariamente el único. A la vez, se minimiza, sistemáticamente, la relación biológica y epigenética que puede haber entre la gestante subrogada y el bebé que gesta y al que da a luz, en un esfuerzo de cortar o limitar el desarrollo de parentesco en esa dirección.

El hilo de la "ley" como configuradora del parentesco se ha trabajado menos, en relación con estas modalidades más novedosas de reproducción humana, con notables excepciones como el libro de la socióloga Markens (2007) y el de la antropóloga Melhuus (2012). Esto no quiere decir que falte esta vertiente en las etnografías sobre el tema; está especialmente presente en las que tratan la gestación subrogada transnacional (Melhuus, 2010; Pande, 2014; Deomampo, 2016, entre otros), donde entran en conflicto los distintos marcos legales de los países de origen de los padres intencionales y los países de destino para la subrogación.

La intención-elección aparece, como ya se ha mencionado, no solo en la toma de decisión por parte de los padres intencionales de crear, por medios tecnológicos extraordinarios, 
un bebé que cuidarán y educarán, sino en la elección del destino para la gestación subrogada, en la elección de donante de semen y/o de óvulo, o de embrión, y en la elección de mujer gestante, aunque esta última, en algunos casos como el de los Estados Unidos, es más bien una elección mutua en la que la gestante también elige a las personas por las que va a gestar.

El estudio de las distintas esferas en las que los procesos de gestación subrogada producen efectos, revela distintas versiones de las etnoteorías del parentesco y la reproducción humana. En los procesos biomédicos, ya que el propósito es paliar una infertilidad o satisfacer un deseo de tener un hijo de unas personas que no quieren/pueden lograr este fin de otra manera, son los padres/madres intencionales, independientemente de su aportación o falta de aportación de sustancia genética, los que siempre se configuran como los sujetos reproductores y los referentes de parentesco (Thompson, 2005). Esto se ve claramente en cualquier página web de una clínica o agencia de gestación subrogada. Las disposiciones legislativas de los distintos países, en cambio, pueden contemplar definiciones muy diversas de paternidad y maternidad, muchas de ellas muy anteriores a las NTRAs y a la gestación subrogada, a veces, con disposiciones específicas para este caso. Las leyes pueden fundamentar la paternidad y/o maternidad en el parto, en la relación de conyugalidad (o su equivalente), en la procedencia del material genético, o en la intención. Así, una madre intencional será legalmente -en los Estados Unidos y, si se acepta el documento del registro estadounidense en España- la madre del bebé nacido mediante un contrato de subrogación en California, avalado por un juez; pero esa misma madre intencional, incluso aunque proporcione el óvulo para la formación del embrión, no será considerada madre del bebé si nace por subrogación en el país de Georgia, por ejemplo, teniendo que empezar el proceso de adopción a la vuelta a España (Álvarez Plaza, Rivas Rivas y Jociles Rubio, 2016). De esta manera, estos tres elementos, naturaleza, ley e intención-elección, se enredan inevitablemente en los procesos reales de la subrogación.

Como se ha mencionado, las propias etnoteorías del parentesco y de la reproducción humana de las personas pueden cambiar -o no- cuando se enfrentan a la necesidad de recurrir a la gestación subrogada para cumplir su deseo de tener hijos. Melhuus (2012: 23-45) ha explorado este fenómeno en la definición de own child de las personas que deben utilizar distintas NTRAs o gestación subrogada para tener hijos. En el caso de vivir en un país, como España, que no permite la gestación subrogada, este proceso de revisión de la propia etnoteoría puede llevar a un enfrentamiento entre las leyes, que reflejan e influyen en las etnoteorías generalmente sostenidas en el contexto, y la legitimidad en la que se posicionan las personas quienes acuden a la gestación subrogada transnacional y vuelven, demandando la ciudadanía para los hijos nacidos al margen o en contra de la legislación nacional. A su vez, hemos percibido que estos casos se representan en los medios de forma muy diversa, según la etnoteoría en la que son enmarcados.

Estas consideraciones, necesariamente breves y presentadas de manera básica aquí, permiten ver lo fructífero que puede ser analizar los distintos elementos y procesos involucrados en la gestación subrogada desde la perspectiva de la antropología del parentesco y, particularmente, desde las etnoteorías del parentesco y la reproducción humana.

\section{La gestación subrogada desde una perspectiva transnacional}

Julio y Ramón viajaron a California (Estados Unidos) hace unos años para tener a su hijo mediante la gestación subrogada. Esta decisión fue tomada tras desechar la adopción internacional debido a los muchos obstáculos que parejas del mismo sexo tienen para adoptar en la mayoría de los países. Después de decidirse por la subrogación transnacional y de salvar el obstáculo económico que, según ellos, fue el mayor de todos, utilizaron todos sus ahorros y recurrieron a la ayuda económica de sus familiares más cercanos. La elección del estado norteamericano de California, uno de los pocos estados en Estados Unidos donde 
esta técnica de reproducción asistida es legal, se debió, entre otras razones, a que contaba con representantes de agencias en España, a la mayor posibilidad de encontrar personas que hablasen español y al reconocimiento legal de ambos como padres antes del nacimiento de su hijo una vez que la gestante renunciara a derechos parentales. Así y todo, mientras en sus respectivas familias la decisión de recurrir a la gestación subrogada transnacional para tener su primer hijo fue recibida con entusiasmo, no recibieron el mismo apoyo y aceptación de todos los miembros de la asociación de familias homoparentales a la que se habían unido para prepararse para su futura paternidad 5 .

Este caso, entre otros, ilustra cómo en España aunque la gestación subrogada no está permitida por la legislación (Art. 10.1 n. 126, 26 de mayo de 2006), un número cada vez mayor de ciudadanos españoles han tenido sus hijas/os recurriendo a la subrogación transnacional -ya sean familias monoparentales, heteroparentales y homoparentales constituidas por varones (Brunet et al., 2013; Álvarez Plaza et al., 2016). Después de la aprobación en España del matrimonio igualitario o de personas del mismo sexo, incluyendo el derecho a la adopción (Ley 13/2005), cambios legislativos en países emisores de menores para la adopción, parecen incidir en la tendencia cada vez mayor de parejas del mismo sexo constituidas por varones que acuden a la gestación subrogada en aquellos países donde ésta se permite (Pichardo, Stéfano y Martín-Chiappe, 2015; Sánchez Molina, 2014).

Las dificultades que, por otra parte, algunas de estas parejas tuvieron años atrás para registrar a sus hijos en España ha provocado intensos y polarizados debates públicos en la sociedad en general (Marco Molina, 2013) y en el mismo seno de asociaciones de familias homoparentales en torno al derecho a la gestación subrogada, la libertad reproductiva, su comercialización y la explotación de la mujer (Scheper-Hughes y Wacquant, 2002). Y es que en contextos del tardo-capitalismo, un número cada vez mayor de personas procedentes de países industrializados donde la gestación subrogada no se permite o está prohibida viajan no solo a Estados Unidos y Canadá y hasta recientemente a países en desarrollo como India o Tailandia o, en la actualidad, a Ucrania y Georgia, donde ésta resultaba más económica (Pande, 2011; Vora, 2013; Whittaker, 2014). Nos encontramos, por lo tanto, ante estructuras económicas y políticas que sitúan la reproducción de estas familias en la intersección de lo nacional con lo global y que afecta no solo a la gestación subrogada, sino a otros modos de reproducción, como la adopción internacional, que se llevan a cabo en contextos de carácter transnacional (Sánchez Molina et al., 2014).

Como se ha destacado previamente, puesto que la gestación subrogada no se contempla como técnica de reproducción asistida en la legislación española, ésta solo reconoce como madre legal a la gestante (Marco Molina, 2013). De ahí la negación años atrás de funcionarios españoles de registrar a los hijos de parejas gays nacidos en el extranjero a través de la gestación subrogada. La reclamación de estas parejas a que sus hijos fueran reconocidos como ciudadanos españoles hizo que la Dirección General de los Registros y Notariados aprobara una provisión permitiendo su registro como hijos legítimos el 5 de octubre de $2010^{6}$.

\footnotetext{
5 Este material procede de la etnografía multi-situada "Las familias "tardías": estudio etnográfico delas conformaciones familiares en Madrid y sus implicaciones sociales" llevada a cabo por los autores y financiada por el programa I+D+i (FEM2011-30306). Mientras la mayoría de las madres que participaron en esta investigación decidieron tener su primer hijo recurriendo a la reproducción asistida y a la adopción internacional, las parejas del mismo sexo de mujeres tuvieron sus hijos a través de la reproducción asistida y las de varones a través de la adopción y la subrogación transnacional (Sánchez Molina et al. 2015).

6 Basándose en el principio de preservar "el mejor interés del menor" esta provisión permite a estos padres registrar a los menores nacidos a través de la subrogación transnacional que acrediten la filiación de los hijos por jueces autorizados en los países emisores siguiendo los procedimientos legales en España y la presentación de un certificado válido que garantice la renuncia de las gestantes a los derechos filiales de los hijos (Marco Molina 2013).
} 
En cualquiera de los casos, la gestación subrogada transnacional -así como la adopción internacional- se está desarrollando en contextos de globalización como fenómeno de reproducción de la familia más allá de fronteras nacionales, originando movimientos transfronterizos de personas, gametos, embriones y gestantes. Y como en los casos que se han ido sucediendo en España en los últimos años, su demanda deviene como consecuencia de distintas legislaciones nacionales que propician su comercialización internacional (Whittaker, 2014). Puesto que la gestación subrogada está prohibida en la mayoría de los países industrializados -con excepción de algunos estados norteamericanos y con restricciones en países como Reino Unido, Grecia y Portugal (Brunet et al., 2013; Álvarez, Rivas y Jociles, 2016)-, ésta genera, asimismo, relaciones asimétricas de género, clase, orígenes étnicos y nacionales. De ahí que su incremento internacional provoque reacciones encontradas tanto en las sociedades emisoras (donde se subroga) como receptoras (se benefician) que cuestionan éticamente regulaciones nacionales y condiciones sociales bajo las que esta técnica de reproducción asistida se ejerce (Bergmann, 2011; Deonandan, Green y van Beinum, 2012).

Su extensión internacional, por otra parte, no solo deja al descubierto aspectos éticos, políticos y económicos, sino también culturales con respecto a las motivaciones, posicionamientos y disposiciones de las gestantes en los que su práctica es legal o no está regulada. De ahí la necesidad de analizar este fenómeno tanto en países emisores como receptores, ya sea desde la economía política o la economía moral (Whittaker, 2014). Es decir, desde una perspectiva transnacional que posibilite superar epistemologías de carácter nacionalistas para analizar éstas y otras intersecciones globales/locales y sus consecuencias socioculturales (Sánchez Molina, Tomé Martín y Valencia, 2009). Con este enfoque, al tiempo que permite superar lo que algunos autores han denominado "nacionalismos metodológicos" (Llopis Goig, 2007), posibilita analizar la reproducción transnacional de la familia teniendo en cuenta procesos políticos-económicos ligados a la expansión global del capital (Ong, 2010; Whittaker y Speier, 2010).

La reproducción de la familia en los actuales procesos de globalización hace necesario, por lo tanto, que los estudios de parentesco tengan en cuenta su diversificación en las sociedades contemporáneas en aquellos ámbitos sociales transnacionales donde ésta se da -ya sea a través de la gestación subrogada o la adopción internacional. De ahí que a partir de la investigación etnográfica sobre familias "tardías" previamente mencionada (Sánchez Molina et al., 2015), se haya incluido una perspectiva transnacional para analizar el recurso que a la subrogación internacional se está dando en las diferentes familias españolas; propuesta epistemológica que no solo nos permite tener en consideración cómo la economía global y las condiciones nacionales afectan su creciente expansión internacional, sino su incidencia en las desigualdades de género, clase y étnicas tanto en países emisores como receptores.

\section{El ethos actual de la maternidad a través de la gestación subrogada}

Las nuevas tecnologías en reproducción asistida y especialmente la extensión de la práctica de la gestación subrogada, han supuesto un cambio necesario, por el desdoblamiento de la figura de lo que antes era la madre, en el ethos occidental de la maternidad ${ }^{7}$.

7 Ethos es definido en el Cambridge Advanced Learner's Dictionary, 4th Edition, como "the set of beliefs, ideas, etc. about the social behaviour and relationships of a person or group", el cuerpo de creencias, ideas, etc. que una persona o grupo tiene sobre el comportamiento y las relaciones sociales. El Diccionario de la Real Academia de la Lengua en su edición del Tricentenario lo define como "Conjunto de rasgos y modos de comportamiento que conforman el carácter o la identidad de una persona o una comunidad". Estas dos definiciones pueden ser completadas con aquellas que desde la estética y la filosofía Aristotélica lo refieren como estatismo emocional, lo que de esencial y permanente tiene un periodo o época artística, y como la imagen que el orador da de sí mismo a través de la retórica o la oratoria. Ethos es así mismo la raíz etimológica de ética, lo que implica no 
Se plantea una definición de ethos como una suerte de cristalización o sedimentación espacio-temporal de comportamiento social de individuos -o grupos o categorías de estosa la hora de definir una identidad -como algo idéntico a sí mismo-, esencial, constante y normativo.

Aplicando esta comprensión a la categoría de "madre", el ethos ha de hablarnos de esos supuestos rasgos constantes, conformados por modos de comportamiento estables y reiterados, que junto a conjuntos de creencias sobre las relaciones sociales y las conductas, conforman el carácter y la forma del ser "madre". Tales ethos serán, sin duda, variables tanto históricamente como individualmente, según nuestras definiciones de partida. Pero esta variabilidad se enfrenta a dos límites, la costumbre para el grupo y la identidad para el individuo. Tales límites se verán delineados por la ética o el deber ser. Como veremos, esta variabilidad se enfrenta, en el caso de la gestación subrogada, con una serie de condiciones que responden a los cambios que se plantean en la relación entre la figura de la madre y el cuerpo gestante. Esta relación nos lleva a reformular las implicaciones históricamente coconstituyentes entre la mujer, el cuerpo sexuado, la reproducción y la maternidad.

Si bien el ethos de una madre será diferente en diversos momentos históricos y contextos sociales, admitirá una continuidad interna al grupo en cada uno de esos momentos y lugares. El ethos de la maternidad en las sociedades occidentales está fuertemente asido al ethos de la feminidad ya desde la concepción finalista implícita en la filosofía naturalista de Aristóteles (Guillaumin, 1978: 9). La modernidad actualizó el naturalismo -y su idea de la diferente naturaleza de hombres y mujeres- sumándole una pretensión determinista (Guillaumin, 178: 5) que caracterizaría los escritos científico-filosóficos que sobre la definición de la mujer comienza a prosperar como respuesta al principio de igualdad del género humano (Hernández Corrochano, 2012: 33). Los ilustrados elevarían una construcción de la mujer centrada en su papel reproductivo que la sujetaría fuertemente al ámbito de la naturaleza mientras que, como ser social que es, la mujer era necesariamente definida en sus comportamientos sociales. Esto dio lugar a una doble definición de orden natural y moral, cuyo elemento central es la maternidad. Jean-Jaques Rousseau, en el Discurso sobre el origen y fundamentos de la desigualdad entre los hombres, establece en su supuesta secuencia evolutiva un estado cero en el que aparece el hombre natural, desprovisto de toda forma, intención o capacidad de generar desigualdad o conflicto. Ya en este estado primigenio el hombre percibiría a la hembra como un bien -de carácter sexual- (íd. 2012: 84) y existirían las madres. Estas últimas encarnarían ya ciertos aspectos éticos: la piedad y la ternura, únicas virtudes naturales, "natural que las mismas bestias dan a veces signos de ella" (íd.: 102), existentes en este primer supuesto periodo. Nótese que la maternidad es, en este supuesto estado primigenio, lo que dota de conducta ética a las mujeres, pues como se recoge en esta cita las madres "amamantaban a sus hijos por necesidad propia pero luego [...] los alimentaban por la suya" (Hernández Corrochano: 91), es decir, entre los esenciales valores que definirán el deber ser de las madres aparecen la entrega y abnegación. A lo largo de los sucesivos periodos expuestos por Rousseau, los hombres evolucionan en una suerte de desarrollo de la desigualdad humana, desigualdad que no afecta a las mujeres puesto que estas, en realidad, no parecen salir nunca del estado primigenio, en el que ya eran naturalmente diferentes. Las mujeres quedan así restringidas en su ámbito de acción al entorno doméstico, en el que desarrollan sus pobres capacidades en espera de su único destino social: dar a luz y cuidar en el ámbito familiar. La naturaleza femenina, definida por filósofos y médicos desde y hacia su útero (Laqueur, 1994), generará así un arquetipo femenino cuya única posibilidad natural de realización éti-

sólo un ser, sino un deber ser.

A partir de estas definiciones podemos plantear el ethos como una suerte de cristalización o sedimentación espacio-temporal del comportamiento social de individuos -o grupos o categorías de estos- a la hora de definir una identidad -como algo idéntico a sí mismo-, esencial, constante y normativo. 
ca es la maternidad. Un ser controlado por los sentimientos e impulsos, instintivo e infantil, que necesita tutela constante y que alcanza, sin embargo, un estado de perfección moral al abrazar la maternidad, "única forma de expresar su esencia de mujer" (Méndez, 2007: 28).

La identificación entre la madre y la mujer como categorías -tanto del ser como del deber ser-, sumada a los supuestos sentimientos o actitudes de cuidado, ternura y piedad que las madres sienten y ejercen sobre sus vástagos, junto a su capacidad de adelantarse a las necesidades de otros y su supuesta sensibilidad e intuición, han sido fundamentales para considerarlas en las sociedades occidentales como las keepers of the heart (Fischer y Manstead, 2000: 71). Incluso desde posiciones feministas, como la de Charlotte Perkins Gilman en el siglo XIX, que defenderán posteriormente las diferencialistas, se apuesta por "los valores y virtudes femeninos más altruistas [...] cuyas principales depositarias serían las madres" (Méndez, 2008: 107). Esta visión de cercanía a la reproducción y la fisiología sitúa a las mujeres más cercanas al ámbito de la naturaleza (Ortner, 1979: 115). Para el pensamiento moderno, cuyo principal fundamento es la separación de la naturaleza y la cultura en dos zonas ontológicas por completo distintas (Latour, 2007: 28), esto se construye como una serie de categorías dicotómicas que polariza en dos tipos de sujetos: hombre y mujer; dos tipos de naturalezas: cultural y natural, y dos ethos: lógica-racional y emocional-instintiva (Lloyd, 1984; Shields, 1984). El ethos de la mujer-madre aparece definido, en la trayectoria histórica de esta perspectiva heteropatriarcal -marcada por el cartesianismo, desde criterios dicotómicos que lo colocan en una fuerte relación con el cuerpo, la fisiología y la emoción por oposición a la razón, el conocimiento, lo cultural y lo masculino. Lo emocional, ligado a la pasión y la víscera, aparece ligado al cuerpo como instintos bajos, frente a lo mental (Shilling y Mellor, 1996 citado en Ramirez, 2001). El cognitivismo separa procesos mentales en superiores e inferiores, entorpeciendo emociones y sentidos a la razón objetiva, siendo esta el mayor logro de la filosofía occidental moderna (Latour, 2007).

Esta relación automática que queda establecida entre el cuerpo, la emoción, el sentimiento y la maternidad va a hacer que sean las feministas las que elaboren el camino de las respuestas, por múltiples vías -ya desde la vindicación feminista, tanto en cantidad como en enfoques. A partir de la tercera ola del movimiento feminista (Valcárcel, 1997, 93) y con la doble entrada de la mujer en la academia -como sujeto que estudia y como objeto de estudio- (Méndez, 2008), se va a producir un resurgimiento del interés por el cuestionamiento de estas dicotomías. El estudio del cuerpo en relación al sujeto, tanto como el cuestionamiento de la filosofía racionalista en su dicotomización masculino/femenino, van a ser factores determinantes en este resurgimiento del interés en lo emotivo que surge desde los ochenta (Williams, 2001: 1-16).

La propia disciplina antropológica ha reaccionado a este interés por lo corporal desde los 80, estableciendo confluencias con el neo-darwinismo, la ecología humana o las ciencias cognitivas entre otros. Uno de los intentos más constantes y coherentes, desde finales de la década de los ochenta se debe a Tim Ingold (1986; 2000; 2011), cuyo planteamiento centrado en la ontogenia permite la re-integración del ser humano tras su moderna descomposición disciplinar (Geertz, 1987). En esta misma línea y siguiendo a Eugenia Ramírez Goicoechea, este debate entre razón/emoción masculino/femenino nos retrotrae a tres problemas relacionados que afectan tanto a nuestro objeto de estudio como a nuestra forma de estudiarlo en diferentes niveles: en primer lugar el problema de la unicidad de la especie y la universalidad de las emociones; en segundo lugar el dualismo cognición/emoción; y por fin la profunda implicación entre el aspecto social y emocional del desarrollo ontogénico del sujeto, la dimensión experiencial (Ramírez Goicoechea, 2001). Desde una perspectiva teórica que se adhiere al estudio del complejo proceso experiencial del ser humano, compuesto por lo físico y lo psíquico tanto como por lo social, el estudio del ser humano pasa necesariamente por contemplar la emoción como "un campo constitutivo/constituido de la experiencia encarnada de un sujeto biopsicológico-social construido sociohistórica y polí- 
ticamente a partir de diversas ideologías -morales- [éticas] y tecnologías educativas y del cuerpo a lo largo de la continua ontogenia del ciclo vital humano" (Ramírez Goicoechea, 2001, 190).

Pensar la maternidad desde una vivencia integrada del cuerpo sensible en proceso de aprendizaje relacional constante nos permite enfrentar el ethos maternal como un constructo que problematizar y descomponer, tanto en su normatividad ética del deber ser, como en su definición esencialista del ser. Este enfoque permite enfrentar las emergencias de prácticas sociales de manera integrada.

Es precisamente desde este enfoque, poniendo el énfasis en la implicación de los aspectos emocionales, desde el que la gestación subrogada aparece como un espacio de indudable interés para la investigación de la vivencia de la maternidad. La gestación subrogada nos permite explorarla desde una multiplicidad de posiciones que hasta ahora parecían ser la misma figura: la madre. La gestación y el cuidado resultan ahora en procesos que se llevan a cabo por distintos agentes, lo que produce un choque con el ethos de la maternidad ya expuesto, debido a que suscita auténticos dilemas sobre nuestras etnoteorías de lo que una madre es. Si las emociones encarnan la experiencia en el cuerpo gestante y este se desvincula emocionalmente y físicamente -tras el nacimiento- del feto, ¿qué sucede con las perspectivas de la maternidad como proceso instintivo y natural? ¿Se disgregan los aspectos biológicos y psicoculturales? ¿Se re-integran en otras formulaciones? ¿Poseen las madres intencionales las supuestas virtudes naturales propias de toda fémina? Todas estas y otras muchas cuestiones que tienen que ver tanto con la separación/duplicación de la figura maternal y con ella la separación de los procesos en algo que puede ser entendido como biológico/social ${ }^{8}$ como con el género y sus atribuciones, nos llevan a plantearnos la transformación del entendimiento social del proceso de parentalidad, a través de ese cambio en el ethos de la maternidad que implica necesariamente la gestación subrogada. Este cambio, este nuevo ethos, sólo puede aprehenderse desde la pregunta a sus agentes protagonistas, una pregunta que pasa por entender esas distintas vivencias de forma encarnada en su propia ontogenia, en su contexto, en su espacio sociopolítico, cognitivo, emocional y corporal.

\section{La gestación subrogada a la luz del concepto de reproducción}

Henrietta Moore (1991) señala como, a mediados del siglo pasado, Edholm, et al. (1977), Harris y Young (1981) critican los postulados seguidos por algunos teóricos marxistas que identificaban reproducción de la mano de obra con reproducción humana, abogando por aplicar a los estudios empíricos un concepto de reproducción que distinguiera analíticamente "tres procesos reproductores distintos que... deberían estudiarse por separado: la reproducción social, la reproducción de la mano de obra y la reproducción humana o biológica" (Moore, 1991: 71). Estas autoras proponen entender por reproducción social, la reproducción de las condiciones de la producción social en su totalidad, buscando qué estructuras deben de reproducirse para que esta se lleve a cabo. Por otro lado, distinguen reproducción de mano de obra y reproducción biológica, entendiendo que esta última siempre ha estado regulada y sometida al control social (Méndez, 2007: 163-165).

En este apartado abogamos por aplicar este enfoque al estudio de la gestación subrogada, presentada por algunos de sus defensores como una técnica más de reproducción asistida donde la gestación es una parte del proceso, mientras que para sus detractores es una explotación del cuerpo de las mujeres, utilizado como herramienta para la realización de un trabajo -el de crear un bien para otros- (Tabet, 2005). Ambas posturas, que dan importancia a aquello que hace de la gestación subrogada un servicio polémico -el desarrollo del embrión en el cuerpo de un sujeto con el que socialmente no va a estar vinculado-, nos lleva en

$8 \mathrm{Y}$ con esto incluso el planteamiento materialista de la externalización de servicios de unas mujeres a otras en las tareas de reproducción (Edholm, Harris y Young, 1982). 
primer lugar a céntranos en la gestación como una parte del proceso procreativo, para luego tratar cuestiones que nos ayuden a su comprensión desde una perspectiva social y feminista.

En lo que se refiere al proceso procreativo son muchas las tesis feministas que han trabajado cuestiones como el embarazo, el parto o la lactancia en diferentes momentos y contextos históricos (Narotzky, 1995). Uno de estos trabajos, el de Paola Tabet (1985), aborda en su estudio sobre la reproducción la lactancia como un servicio mercantilizado en siglos pasados a través de la figura de las nodrizas. Establecer una comparación entre la lactancia y la gestación subrogada, ambas remuneradas en el proceso de la reproducción humana ${ }^{9}$, nos lleva a reflexionar sobre el significado del embarazo entendiéndolo potencialmente como un trabajo - o acaso empleo- vinculado a la reproducción social y a la fuerza de trabajo. Pues la gestación, al igual que el amamantamiento, conlleva un gasto de energía por encima del metabolismo basal (Tabet, 1985: 124) y "crea y produce algo que no es autoconsumido ni indispensable para la conservación del propio individuo reproductor" (Narotzky, 1995: 69-70).

Este planteamiento economicista e industrial, donde gestar cobra un valor monetario y se normaliza dentro del proceso de la procreación, nos permite también pensar este trabajo en términos de explotación. Una explotación que vendría secundada por la pérdida del control en la gestación que han sufrido las mujeres occidentales desde hace décadas, debido a un control médico que ha ido aumentando paulatinamente junto con los cuidados antenatales. Esto, según Susana Narotzky, ha supuesto que las mujeres hayan perdido el control de sus embarazos "...expropiando a la mujer embarazada de sus criterios de "subjetivos'... [que] son automáticamente descartados mediante criterios científicos." (Narotzky, 1995: 55-56).

A esta realidad genérica que sufren las mujeres habría que añadir la intervención y control que las clínicas de reproducción hacen de la fecundación, disociada del acto sexual en las TRA, y de la implantación del embrión, que en la gestación subrogada conlleva la preparación del endometrio de la gestante buscando los momentos adecuados para la concepción $^{10}$. En este sentido, aunque las responsabilidades del proceso reproductor en la gestación subrogada se distribuyan socialmente entre las gestantes, las clínicas y/o los padres intencionales, el control de la producción está en manos de aquellos que manejan la tecnología, cada vez más compleja y avanzada (Tabet, 2005: 64), limitando la capacidad decisoria de la gestante sobre su trabajo, que a tiempo completo es inseparable de su contexto cotidiano y de sus relaciones sociales, y que marcará su vida durante los nueve meses que dura el embarazo. Este control que ejercen las clínicas y agentes que intervienen en la contratación del servicio de la gestante se extiende también a su vida sexual, a sus hábitos de vida e incluso a su personalidad, en aras al bienestar del feto, pues los intermediarios no solo determinan los perfiles de sus gestantes valorando sus cualidades físicas, sino también psicosociales y de "afinidad de ideas" con los padres intencionales"

Pese a todo, este enfoque materialista sobre la gestación subrogada como "un proceso tecnológico constituido por secuencias de una cadena operativa, [cuya] fragmentación metodológica...define los lugares donde es posible la intervención y el control técnico" (Narotzky, 1995: 69-70), no interfiere en el entendimiento de la reproducción humana como un hecho natural. La percepción que tenemos todos los sujetos, incluida la comunidad médica, sobre la gestación, sigue siendo biologicista y por lo tanto reticente a hablar de salario o de trabajo en el acto de gestar ${ }^{12}$.

9 http://embarazoyparto.about.com/od/QuedarEnEmbarazo/a/Maternidad-Subrogada-Costo-Y-Los-RequisitosPara-Dar-Un-Vientre-En-Alquiler.htmEn http://www.surrogacymed.es/maternidad-subrogada/precios-new. html, se especifica la remuneración económica de la mujer que subroga en la gestación subrogada.

$10 \mathrm{http}: / /$ www.babygest.es/preparacion-del-endometrio/

$11 \mathrm{http} / / /$ aeges.es/preguntas-frecuentes-sobre-la-gestacion-subrogada-o-vientre-de-alquiler/

12 En http://www.surrogacymed.es/maternidad-subrogada/precios-new.html, una prestigiosa empresa de subrogación rusa, se habla de compensación económica, divida en partidas, que recibe la mujer gestante. 
Esta concepción natural de la reproducción biológica, según la crítica feminista, parte de un planteamiento teórico occidental que deja a las mujeres y las actividades que realizan en lo doméstico fuera de la población activa. La procreación, por lo tanto, pasa a ser una actividad privada cuya aportación a la reproducción social y de mano de obra es nula (Moore, 1991: 71-72). En este sentido, aunque las TRA hayan externalizado determinadas fases de la reproducción humana, entre ellas de la fecundación y la gestación, esto no ha tenido como consecuencia dejar de ver al hecho procreativo como acto íntimo y doméstico yuxtapuesto al ámbito público y a las relaciones de mercado (Moore, 1991: 38).

Así, con el fin de evitar este sesgo occidental de lo natural, que mantiene la reproducción biológica en lo privado (Moore, 1991: 37), los análisis sobre la gestación subrogada no deberían sustraerse de las relaciones sociales que se desarrollan en y entre los países que la reconocen o la prohíben. En consecuencia, como señala Verena Stolcke (1986), es necesario examinar "las nuevas técnicas de reproducción [unidas] al análisis de las políticas eugenésicas en los países industrializados occidentales, de las políticas de control de la natalidad en países del Tercer Mundo o del control de la inmigración”, entre otras cuestiones (Narotzky, 1995: 71) ${ }^{13}$.

Ampliar el espectro conlleva entender la gestación subrogada y el control tecnológico de la reproducción humana dentro de los contextos socio-culturales en los que se producen, donde las desigualdades de acceso a los recursos, ya sean materiales o científicos, de autonomía de los sujetos o de derechos, reproducen ideologías de subordinación de unos sobre otros. En este sentido, tenemos que tener en cuenta que "la inferencia causal de que a mayor desarrollo tecnológico, mayor capacidad de elección y por lo tanto mayor control de la mujer implicada en el proceso reproductivo, que ha sido propuesta por la profesión médica occidental, no parece tan clara" (Franklin y McNeil, 1988, en Narotzky, 1995: 73). Pues para algunos autores, el concepto de elección no deja de ser un artificio del "humanismo liberal" que se basa en un supuesto de igualdad que en realidad esconde grandes diferencias entre los sujetos.

Así, la libertad de elección que se otorga a la gestante está tan condicionada por el sistema como la de la madre intencional, lo que nos presenta situaciones complejas donde las relaciones de poder y la diferencia de acceso a los recursos permiten a algunas mujeres apropiarse de la fuerza de trabajo de otras ${ }^{14}$. En consecuencia, cuestiones como el estudio de identidad maternal, la fecundidad "natural", o las políticas de adopción, nos adentran en debates tan complejos como la ineficacia de las políticas demográficas de los países occidentales.

Siguiendo esta argumentación, las clínicas de reproducción y la industria genética ${ }^{15}$ se podrían analizar como mantenedoras de aquellas estructuras que reproducen las condiciones de producción social y que, a su vez, favorecen la intervención tecnológica en la reproducción humana ${ }^{16}$. Estas estructuras, muchas causantes de la desigualdad de géneros,

13 ... [las] nociones individualistas y biogenéticas de la maternidad y de la paternidad hasta el punto de que para las nuevas tecnologías reproductivas se instaura un control del material genético donado que permita a los receptores elegir rasgos fenotípicos, con el fin de que el futuro bebé se aproxime al máximo al ideal biogenético. (Verena Stolcke 1986, en Narotzky, S. 1995-71)

14 La gestación subrogada es utilizada mayoritariamente por parejas heterosexuales. http://www.rtve.es/ noticias/20140801/preguntas-respuestas-sobre-gestacion-subrogada-vientres-alquiler/976260.shtml

15 http://www.elmundo.es/salud/2016/02/01/56af301346163fd8218b4576.html

16 Bajo el epígrafe, ¿Quieres cumplir tu sueño?, una clínica de fertilidad se pregunta: ¿Influye nuestro estilo de vida en la fertilidad? La respuesta es SÍ. Nuestro estilo de vida influye y mucho en la fertilidad tanto del hombre como de la mujer. La infertilidad afecta a millones de parejas en todo el mundo. Además de retrasar la edad de ser madre, existen ciertos hábitos que perjudican la fertilidad, según diferentes estudios. El estrés, la mala alimentación, la falta de ejercicio, el tabaco, el alcohol, el consumo de ciertas drogas y medicamentos, tienen efectos en el semen del hombre y en el ciclo ovárico de la mujer. Igualmente estar demasiado delgado y el so- 
consolidan modelos de vida y estereotipos que afectan profundamente a la fertilidad de las mujeres -en particular- y de los sujetos en general: mala alimentación, sobrepeso, exceso de ejercicio físico, estrés, largas jornadas laborales, desigualdades de poder, en suma, modelos sociales de masculinidad y feminidad.

En resumen, los efectos de las TRA dependen de quien controle los conocimientos y la tecnología, de quien decide su aplicación y de quienes tiene acceso a estos recursos, sus circunstancias y las condiciones. Si bien los adeptos a la gestación subrogada la presentan como una técnica beneficiosa para las parejas que no pueden tener hijos y desean un bebé genéticamente propio, este discurso puede esconder ideologías sexistas, clasistas y racistas que se apoyan en estructuras específicas de desigualdad. Pero también hay que valorar que la tecnología, en sí misma, no puede calificarse tampoco de perversa para determinados individuos o grupos sociales, sino que hay que situarla "en su contexto social y percibir las relaciones de poder y control sobre la procreación que puede establecerse a través de ella" (Narotzky, 1995: 58).

\section{Conclusiones}

Este artículo, que ofrece distintos abordajes sobre un mismo tema pretende, en sí mismo, mostrar la primera fase de un método de trabajo que el equipo de investigación de la UNED, Familia y Parentesco en el siglo XXI, desarrollamos con buenos resultados en nuestro anterior I+D+i - cuya temática era las Familias Tardías- y que pretendemos implementar en nuestra actual investigación sobre gestación subrogada.

En este sentido, más que los resultados de una investigación en curso, presentamos una metodología que aúna los diferentes intereses de un grupo de investigación con un objetivo final: presentar los resultados de un hecho social desde el pensamiento complejo que nos muestra la realidad social.

En este método de trabajo, donde los integrantes del grupo pertenecen a una disciplina común, la antropología, utilizan las mismas técnicas de trabajo de campo, la historia de vida, y comparten los resultados empíricos, se busca aprovechar al máximo los conocimientos que cada uno puede aportar desde de sus diferentes líneas de trabajo: el parentesco, la trasnacionalidad, la maternidad y la reproducción.

Este diseño, unidisciplinar y multiestatégico, permite a cada miembro del grupo no solo aprovechar sus conocimientos adquiridos en años, sino que le otorga libertad en el análisis de los datos que, después de una puesta en común, confluirán en un único itinerario. Esta fase de trabajo, que se realiza en diferentes seminarios, tantos como líneas de trabajo haya dentro del grupo, retroalimenta la investigación individual con las aportaciones que el resto de los miembros del grupo hacen sobre un tema y un campo que conocen en profundidad.

Así, en este artículo, como ya hemos indicado, presentamos la primera de las cuatro fases de este método de trabajo. En él los investigadores muestran sus objetivos sobre el tema de investigación que, dentro de sus respectivas líneas, parten de los conocimientos adquiridos por todo el grupo de una preliminar prospección del campo. En este sentido, Nancy Konvalinka, valorando la relevancia que en la formación de nuevos modelos de parentesco tiene la gestación subrogada, propone un planteamiento sobre las relaciones simbólicas que conlleva, entre otras cosas, el compartir sustancia. Raúl Sánchez Molina, por su parte, acomete la importancia que tiene en la gestación subrogada la internacionalización de esta práctica, proponiendo un planteamiento teórico trasnacional sobre este hecho. Sandra

brepeso también son factores condicionantes. El sobrepeso afecta a la capacidad fértil de ambos miembros de la pareja y puede causar una tasa de implantación menor, así como una mayor proporción de abortos. En resumen, estos malos hábitos pueden suponer un problema grande a la hora de intentar un embarazo. Una vida más sana, una buena alimentación, ejercicio moderado y tomarse la vida con más calma serán los mejores compañeros de viaje. http://www.irema.org/influye-estilo-vida-la-fertilidad/ 
Fernández, partiendo del imaginario sobre la maternidad en occidente y de una concepción del ser humano como organismo, plantea el estudio de la experiencia de la maternidad como incorporación- a través de las subjetividades de aquellas mujeres que son partícipes en la gestación subrogada. Una práctica que, por otro lado, incluye a varios agentes sociales dependiendo de la fase del proceso de reproducción y que será el tema de estudio de Elena Hernández Corrochano.

\section{Bibliografía}

Álvarez Plaza, C.; Rivas Rivas, A. M.; Jociles Rubio, M. (2016). "Estrategias de creación de vínculos en la subrogación gestacional: diferencias según los países de origen de los hijos/as", en M. I. Jociles Rubio (Ed.), Revelaciones, filiaciones y biotecnologías. Una etnografía sobre la comunicación de los orígenes a los hijos e hijas concebidos mediante donación reproductiva. Barcelona: Edicions Bellaterra. 317-346.

Bergmann, S. (2011). "Fertility tourism: Circumventive routes that enable access to reproductive technologies and substances." Signs: Journal of Culture and Women in Society, 36(2): 280-289. DOI: $10.1086 / 655978$

Birenbaum-Carmeli, D. ; Inhorn, M. C. (Eds.) 2009. Assisting reproduction, testing genes. Nueva York: Berghahn Books.

Birenbaum-Carmeli, D.; Carmeli, Y. S. (Eds.) (2010). Kin, gene, community. Reproductive technologies among Jewish Israelis. Nueva York: Berghahn Books.

Brunet, L.; King, D.; Carruthers, J.; et al. (2013). Comparative study on the regime of surrogacy in the EU member states. Bruselas: European Parliament. http://www.europarl.europa.eu/ RegData/etudes/STUD/2013/474403/IPOL-JURI_ET(2013)474403_EN.pdf

Carsten, J. (1995). "The substance of kinship and the heat of the hearth: Feeding, personhood and relatedness among Malays in Pulau Langkawi”. American Ethnologist, 22: 223-241. DOI: 10.1525/ae.1995.22.2.02a00010

Deomampo, D. (2016). Transnational reproduction. Race, kinship, and commercial surrogacy in India. Nueva York: New York University Press.

Deonandan, R.; Green, S.; van Beinum, A. (2012). "Ethical concerns for maternal surrogacy and reproductive tourism". Journal of Medical Ethics, 38(12): 742-745. DOI: 10.1136/medethics-2012-100551

Edholm, F.; Harris, O.; Young, K. (1982 [1978]). Conceptualisation des femmes. Nouvelles Questions Féministes, 3: 37-69.

Edwards, J. ; Salazar, C. (Eds.). (2009). European kinship in the age of biotechnology. Nueva York: Berghahn Books.

Fischer, A. H; Manstead, A. S. R. (2000). "The relation between gender and emotions in different cultures", en A. H. Fischer (Ed.), Gender and emotion: Social psychological perspectives (pp. 71-94). Cambridge: Cambridge University Press. https://www.researchgate.net/publication/303253351_The_relation_between_gender_and_emotion_in_different_cultures DOI: $10.1037 / 1528-3542.4 .1 .87$

Franklin, S. (2013). Biological relatives. IVF, stem cells, and the future of kinship. Durham: Duke University Press.

Geertz, C. (1987). La interpretación de las culturas. Barcelona: Gedisa.

Guillaumin, C. (1978). «Practique du Pouvoir et idée de Nature I. L'appropriation del femmes”. Questions feminists, 2: 5-30. http://www.feministes-radicales.org/wp-content/uploads/2010/11/ Colette-Guillaumin-Pratique-du-pouvoir-et-id\%C3\%A9e-de-Nature-1-Lappropriationdes-femmes.pdf

Hernández Corrochano, E. (2012). Teoría feminista y antropología: Claves analíticas. Madrid: Centro de Estudios Ramón Areces.

Hernández Corrochano, E.; Konvalinka, N.; et al. (2016-2018). Madres, sujetos agentes o individuos con agencia. Estudio etnográfico a través de la subrogación gestante. MINECO, Proyecto I+D FEM2016-80012-R. 
Ingold, T. (2011). Being alive: Essays on movement, knowledge and description. Londres: Routledge. (2000). The perception of the environment: Essays on livelihood, dwelling and skill. Londres: Routledge.

(1986). The appropriation of nature: Essays on human ecology and social relations. Manchester: Manchester University Press.

Jociles Rubio, M. et al. (2013-2015). Revelación y secreto de los orígenes en las familias con descendencia por donación de gametos: variaciones según los modelos familiares. MINECO, Proyecto I+D CSO2012-36413.

Knecht, M.; Klotz, M.; Beck, S. (Eds.) (2012). Reproductive technologies as global form. Ethnographies of knowledge, practices, and transnational frontiers. Frankfurt: Campus Verlag.

Konvalinka, N. et al. (2015-2017). Surrogate Paternities/Maternities in Spain: Agencies and Socio-political Structure through Ethnography. Proyecto Santander-UNED, I+D+i Orientada a los retos de la sociedad. 2014I/PPRO/029.

Laqueur, T. (1994). La construcción del sexo. Madrid: Cátedra.

Latour, B. (2007) Nunca fuimos modernos. Madrid: Siglo XXI.

Ley 14/2006, de 26 de mayo, sobre técnicas de reproducción humana asistida.

Llopis Goig, R. (20079. “El ‘nacionalismo metodológico’como obstáculo en la investigación sociológica sobre migraciones internacionales". EMPIRIA. Revista de Metodología de Ciencias Sociales, 13: 101-117. http://revistas.uned.es/index.php/empiria/article/view/1161 DOI: http://dx.doi.org/10.5944/empiria.13.2007.1161

Lloyd, G. (1984). The man of reason: "Male" and "female" in western philosophy. Londres: Methuen.

Marco Molina, J. (2013). "Spanish Law in 2010-2012: The Influence of European Union Law and the Impact of the Economic Crisis". Journal of Civil Law Studies, 6: 401-443. http://digitalcommons.law.lsu.edu/cgi/viewcontent.cgi?article $=1103 \&$ context $=$ jcls

Markens, S. (2007). Surrogate motherhood and the politics of reproduction. Berkeley: University of California Press.

McIntosh, C. (2013). Cambridge Advanced Learner's Dictionary, 4th Edition. Cambridge: Cambridge University Press.

Melhuus, M. (2012). Problems of conception. Issues of law, biotechnology, individuals and kinship. Nueva York: Berghahn Books.

(2010). "Hijos sin madres, padres desconocidos y otros problemas de filiación. Hechos reproductivos e imaginaciones procreativas en Noruega. La historia oficial -y algo más". En V. Fons, A. Piella M. Valdés (Eds.), Procreación, crianza y género. Aproximaciones antropológicas a la parentalidad. Barcelona: Promociones y Publicaciones Universitarias, S.A. 27-42.

Méndez, L. (2007). Antropología feminista. Madrid. Editorial Síntesis.

Moore, H. (1991). Antropología y feminismo. Madrid: Editorial Cátedra.

Narotzky, S. (1995). Mujer, mujeres, género: una aproximación crítica al estudio de las mujeres en las ciencias sociales. Madrid: Editorial CSIC - CSIC Press.

Ong, A. (2010). "Introduction: An analytics of biotechnology and ethics at multiple scales", en A. Ong, Aihwa N. Chen, N. (Eds.), Asian biotech: Ethics and communities of fate. Durham, NC: Duke University Press. 1-51. http://www.aihwaong.info/sg_userfiles/ong_webready_PDF.pdf

Ortner, S. (1979). “¿Es la mujer con respecto al hombre lo que la naturaleza con respecto a la cultura?”, en O. Harris, K. Young (Eds.), Antropología y feminismo. Barcelona: Anagrama. $109-131$.

Pande, A. (2014). Wombs in labor. Transnational commercial surrogacy in India. Nueva York: Columbia University Press.

. (2011). "Transnational Commercial Surrogacy in India: Gifts for Global Sisters?" Reproductive Biomedicine Online, 23(5): 618-625. DOI: 10.1016/j.rbmo.2011.07.007 
Pichardo Galán, J.I.; Barbero de Stéfano, M.; Martín-Chiappe, M. L. (2015). “(Des) naturalización y elección: emergencias en la parentalidad y el parentesco de lesbianas, gays, bisexuales y transexuales". Revista de Dialectología y Tradiciones Populares, 70(1): 187-203. http://rdtp.revistas.csic.es/index.php/rdtp/article/viewArticle/472 DOI: http://dx.doi. org/10.3989/rdtp.2015.01.009

Ragoné, H. (1994). Surrogate motherhood: Conception in the heart. Boulder: Westview Press.

Ramírez Goicoechea, E. (2001). “Antropología 'compleja' de las emociones humanas”. Isegoría, 25: 177-200. http://isegoria.revistas.csic.es/index.php/isegoria/article/viewArticle/589 DOI: http://dx.doi.org/10.3989/isegoria.2001.i25.589

Ramos, R.; Shain, R. N.; y Johnson, L. (1995). “"Men I Mess with Don’t Have Anything to Do with AIDS': Using Ethno-theory to Understand Sexual Risk Perception”. Sociological Quarterly, 36(3): 483-504. DOI: 10.1111/j.1533-8525.1995.tb00449.x

Real Academica Española. (20149. Diccionario de la lengua Española. Madrid: Espasa.

Rousseau, J-J. (1985 [1755]). Discurso sobre el origen y fundamentos de la desigualdad entre los hombres. Madrid: Alhambra.

Sánchez Molina, R. (2014). Ethnographic approaches to late-forming families in Spain: From national to transnational contexts. Paper presentado en el 7th Congress of the European Society on Family Relations en Madrid, 6/9/2014.

Sánchez Molina, R.; Hernández Corrochano, E.; Konvalinka, N.; et al. (2015). Informe Final de Las familias "tardías": estudio etnográfico de las conformaciones familiares en Madrid y sus implicaciones sociales. Madrid: Ministerio de Economía y Competitividad.

Sánchez Molina, R.; Tomé Martín, P.; Valencia, M. (2009). "Nuevos tiempos, nuevas familias: aproximaciones etnográficas en el estudio de configuraciones familiares contemporáneas". Revista Latinoamericana de Estudio de Familia, 1(1): 22-45. http://e-spacio.uned.es/fez/ eserv/bibliuned:500383-Articulos-5920/Documento.pdf

Scheper-Hughes, N.; y Wacquant, L. (2002). Commodifying bodies. Thousand Oaks, CA: SAGE.

Schneider, D. M. (1980 [1968]). American kinship. A cultural account. Chicago: University of Chicago Press.

(1972). “What Is Kinship All About?”, en P. Reining (Ed.), Kinship studies in the Morgan centennial year Washington, D.C.: The Anthropological Society of Washington. 32-63.

Schramm, K; Skinner, D.; Rottenburg, R. (Eds.). (2012). Identity politics and the new genetics. Re/ Creating categories of difference and belonging. Nueva York: Berghahn Books.

Shields, S. A. (1984). “'To pet, coddle and do for.' Caretaking and the concept of maternal instinct”, en M. Lewin (Ed.), In the shadow of the past: Psychology portrays the sexes. Nueva York: Columbia University Press. 256-274. http://www.academia.edu/2264786/To_pet_coddle_ and_do_for_Caretaking_and_the_concept_of_maternal_instinct

Stone, L. 2004a. "Introduction. Part II, Section 4", en R. Parkin, L. Stone (Eds.), Kinship and family. An anthropological reader. Oxford: Blackwell. 331-341.

2004b. "Has the World Turned? Kinship in the Contemporary American Soap Opera", en R. Parkin, L. Stone (Eds.), Kinship and family. An anthropological reader. Oxford: Blackwell. 395-407.

Tabet, P. (2005). "Las manos, los instrumentos, las armas", en C. Ochy, J. Falquet (Eds.), El patriarcado al desnudo: tres feministas materialistas. Buenos Aires: Brecha Lésbica. 57-129. https://julesfalquet.files.wordpress.com/2010/05/el-patriarcado-al-desnudo-tres-feministas-materialistas 2.pdf

(1985). "Fertilité naturelle, reproduction forcé", en N-C. Mathieu (Ed.), L'arraisonnement des femmes : essais en anthropologie des sexes. París-Montreal: L’Harmattan. 70-146.

Teman, E. (2010). Birthing a mother. The surrogate body and the pregnant self. Berkeley: University of California Press.

Thompson, C. (2005). Making parents. The ontological choreography of reproductive technologies. Cambridge: The MIT Press.

Valcárcel, A. (1997). La política de las mujeres. Madrid: Cátedra.

Vora, K. (2013). "Potential risk and return in transnational Indian gestational surrogacy". Current Anthropology, 54(S7): S97-S106. http://www.jstor.org/stable/10.1086/671018?seq=1\#pa ge_scan_tab_contents 
Weston, K. (1991). Families we choose: Lesbians, gays, kinship. Nueva York: Columbia University Press.

Whittaker, A. (2014). "Merit and money: The situation ethics of transnational commercial surrogacy in Thailand". International Journal of Feminist Approaches to Bioethics, 7(2): 100-102. https://transculturalbodies.files.wordpress.com/2017/03/whittaker2014_merit-and-money.pdf

Whittaker, A; Speier, A. (2010). “Cycling overseas': Care, commodification, and stratification in cross-border reproductive travel". Medical Anthropology, 29(4): 363-383. https://www. ncbi.nlm.nih.gov/pubmed/21082483 DOI:10.1080/01459740.2010.501313

Williams, S. J. (2001). Emotion and social theory. Londres: SAGE.

\section{5}

